\title{
Improving the interfacial and mechanical properties of short glass fiber/epoxy composites by coating the glass fibers with cellulose nanocrystals
}

\author{
A. Asadi ${ }^{1}$, M. Miller ${ }^{1}$, R. J. Moon ${ }^{2,3}$, K. Kalaitzidou ${ }^{1,3^{*}}$ \\ ${ }^{1}$ G.W. Woodruff School of Mechanical Engineering - Georgia Institute of Technology, GA 30332 Atlanta, United States \\ ${ }^{2}$ The Forest Products Laboratory, U.S. Forest Service, Madison, 53726 Wisconsin, United States \\ ${ }^{3}$ School of Materials Science and Engineering - Georgia Institute of Technology, GA 30332 Atlanta, United States
}

Received 11 December 2015; accepted in revised form 11 February 2016

\begin{abstract}
In this study, the interfacial and mechanical properties of cellulose nanocrystals (CNC) coated glass fiber/epoxy composites were investigated as a function of the CNC content on the surface of glass fibers (GF). Chopped GF rovings were coated with $\mathrm{CNC}$ by immersing the $\mathrm{GF}$ in $\mathrm{CNC}(0-5 \mathrm{wt} \%)$ aqueous suspensions. Single fiber fragmentation (SFF) tests showed that the interfacial shear strength (IFSS) increased by $\sim 69 \%$ in composites produced with CNC coated GF as compared to uncoated GF, suggesting an enhancement of stress transfer across the GF/matrix interface. The role of CNC coatings on the tensile, flexural, and thermo-mechanical properties of the CNC-coated GF/epoxy composites was investigated. Incorporation of $0.17 \mathrm{wt} \% \mathrm{CNC}$ in the composite resulted in increases of $\sim 10 \%$ in both elastic modulus and tensile strength, and 40 and $43 \%$ in flexural modulus and strength respectively. In conclusion CNC coatings on GF alter the GF/matrix interface resulting in improvement of the mechanical performance of the corresponding composites.
\end{abstract}

Keywords: polymer composites, nanomaterials, coatings, mechanical properties

\section{Introduction}

Short glass fiber (GF) polymer matrix composites (PMC) with 30-50 wt $\%$ fiber loading have been widely used in automotive and marine industries as structural components due to their high specific strength and stiffness. Continued development in light-weighted PMC with higher mechanical performance has been fueled by the premise that $10 \%$ reduction in the vehicle weight can result in $6-8 \%$ increase in fuel efficiency [1]. One approach towards light weighting is the incorporation of nanoparticles either as a reinforcement phase within the matrix polymer, or at the fiber/matrix interface [2-5]. The high surface area per unit volume of nanoparticles enhances the interactions with the other constituents in the composite and subsequently enhances the me- chanical properties compared to larger dimension particles of the same composition [6]. However, issues such as inhomogeneous dispersion and agglomerate formation should be addressed before using these materials in large scale production of composites.

Alternative nanoparticles that have potential for increasing GF-polymer matrix composites properties are cellulose nanomaterials (CNs). $\mathrm{CNs}$ are cellulose-based nanoparticles that are obtained from plants, algae, bacteria and marine animals [7-9]. CN particles are generally grouped based on the cellulose source and the extraction methods, leading to various $\mathrm{CN}$ types, including: cellulose nanocrystals (CNC), cellulose nanofibrils (CNF), algae cellulose (AC), bacterial cellulose (BC), etc. One common trait with all $\mathrm{CN}$ types is the parallel stacking of cellulose

${ }^{\text {*Corresponding author, e-mail: kyriaki.kalaitzidou@me.gatech.edu }}$ (C) BME-PT 
chains along the particle length, and because of this feature the properties of the various CNs are similar to each other, at least within the scatter of experimental testing or atomistic model predictions [9]. With this in mind, as a whole CNs have a unique combination of characteristics [9] that make them attractive for certain composite applications, i.e. low density $\left(1.6 \mathrm{~g} / \mathrm{cm}^{3}\right)$, high surface area and aspect ratio (10-100), tensile strength of 3-7.5 GPa, and elastic modulus of 110-220 GPa, surfaces with accessible hydroxyl side groups (e.g. $-\mathrm{OH}$ ) that can be readily chemically modified, and low toxicity [10]. In addition, CNs extracted from trees and plants have the potential to be produced at industrial scale quantities, and reasonable price [11]. In the current study, the $\mathrm{CN}$ type used was $\mathrm{CNC}$, which are whisker-shaped particles (typically, $3-5 \mathrm{~nm}$ in width and $5-500 \mathrm{~nm}$ in length), extracted by acid hydrolysis of plants [12], and are considered to have properties within the ranges listed above.

There has been considerable interest in CNs as reinforcement in various polymer systems due to their high specific modulus and strength characteristics, and provided that the CNs are well dispersed within the polymer matrix, increases in mechanical performance of the $\mathrm{CN}$-polymer system and subsequently the corresponding composites can be expected. For most epoxy systems, obtaining well dispersed $\mathrm{CNs}$ in epoxies has been exceedingly challenging, especially for high $\mathrm{CN}$ volume fraction [13-20]. To address this issues, waterborne epoxies [14, 15, 18], solvent exchange methods [20,21], CN preforms impregnation [22] and chemical modification of $\mathrm{CN}$ surfaces have been used [23], however, the time and cost involved in these processes limit their capability in industrial scale production of GF/epoxy composites.

An alternative approach has been to add $\mathrm{CNs}$ to $\mathrm{GF} /$ epoxy composites by coating the GF prior to mixing into epoxy, where the $\mathrm{CN}$ coating modifies the GF/ epoxy interface and subsequently improves the properties. A good review on tailoring interphase through coating the fibers in polymer composites can be found in [24]. Chen et al. [25] deposited bacterial cellulose (BC) on the surface of GF during the process of fermentation. The $\mathrm{BC}$ coated GF were subsequently compounded into epoxy, where the increase in the interfacial shear strength (IFSS) of BC coated GF/ epoxy interface was attributed to the increase in interfacial surface roughness and area, and chemical bonding between the $\mathrm{BC}$ coating and the epoxy ma- trix. However, for large volume uses, growth of the $\mathrm{BC}$ film on GF is impractical. Additional work is needed to i) find coating processes that are quick, reliable, and inexpensive and ii) link changes in IFSS to differences in macroscopic mechanical properties of the GF/epoxy composites as a result of the addition of the $\mathrm{CN}$ coatings. To the best of the authors' knowledge, no studies exist on simple coating technique of GF with $\mathrm{CN}$ and the influence of the $\mathrm{CN}$ coating on both the interfacial and mechanical properties. In this study, the effect of CNC coatings on GF on the GF/epoxy matrix interfacial properties and the subsequent influence on the mechanical properties of short GF/epoxy composites are investigated. GF were coated by immersing them in an aqueous $\mathrm{CNC}$ suspension (0-5 wt \%), a scalable technique. Interfacial adhesion was characterized by the IFSS using single fiber fragmentation tests (SFF). Changes in the IFSS and stiffness across the GF/matrix interphase as a result of CNC coating on the GF were two potential mechanisms considered for the enhancement in tensile and flexural properties of $\mathrm{CNC}$ coatedGF/epoxy composites. The optimum CNC concentration on the GF that resulted in the best mechanical performance was determined.

\section{Experimental details}

\subsection{Materials}

Owens Corning (Oak Brook, IL, US) ME1510 multiend roving GF (TEX 48000, single filament diameter of $10 \pm 1 \mu \mathrm{m}$ ) were used as received. The GF rovings were chopped to an average length of $25 \pm 0.5 \mathrm{~mm}$. A bicomponent epoxy resin consisting of 635 thin epoxy and 556 slow amine hardener supplied by US Composites (West Palm Beach, FL) was used. CNC in the form of $11.9 \mathrm{wt} \%$ never-dried suspension in water [26] were supplied by the USDA Forest Service-Forest Products Laboratory (FPL), Madison, WI, USA. The average length and width of the CNC were $138 \pm 22 \mathrm{~nm}$ and $6.4 \pm 0.6$, respectively [18].

\subsection{Coating of GF with $\mathrm{CNC}$ and fabrication of CNC-coated GF/epoxy composites}

$\mathrm{CNC}$ coated GF were produced by immersing $\sim 154 \mathrm{~g}$ of chopped GF rovings in $\sim 1000 \mathrm{~mL}$ of aqueous CNC suspension without agitation for $2 \mathrm{~min}$, after which the GF were taken out and spread on covered trays with ample ventilation to dry $24 \mathrm{~h}$ at room temperature. This simple, low cost coating method is conceptually scalable for larger volume applications. The 
CNC used were not functionalized or surface treated. For uncoated GF, a similar procedure was followed using distilled water with no $\mathrm{CNC}$ to maintain the consistency in fabrication. The $\mathrm{CNC}$ suspension was diluted, in order to adjust the $\mathrm{CNC}$ coating, using distilled water and then sonicated to achieve a uniform $\mathrm{CNC}$ dispersion in water. Sonication was carried out using Misonix S-4000 ultrasonic processor equipped with a $12.5 \mathrm{~mm}$ probe diameter at $30 \%$ amplitude and $20 \mathrm{~W}$ power for $8 \mathrm{~min}$. Aqueous $\mathrm{CNC}$ suspensions of $0,0.5,1,1.5,2,3$ and $5 \mathrm{wt} \%$, were prepared using the above procedure and used to coat the chopped GF rovings. The corresponding naming scheme used to describe the coated fibers is GF, 0.5SGF, 1S-GF, 1.5S-GF, 2S-GF, 3S-GF, and 5S-GF, respectively. The ' $\mathrm{S}$ ' in this case represents the concentration of $\mathrm{CNC}$ suspension.

For SFF test specimen preparation, individual GF filaments were carefully pulled off from the coated and uncoated GF rovings. Subsequently, a single $120 \mathrm{~mm}$ long GF filament was placed in the middle of a dogbone shaped mold and covered with epoxy resin that was cured at $80^{\circ} \mathrm{C}$ for $1 \mathrm{~h}$, followed by post-curing at $100{ }^{\circ} \mathrm{C}$ for $4 \mathrm{~h}$. Prior to pour the epoxy in the mold, the single GF filaments were manually pre-strained and the ends of the GF were taped down to ensure that the GF remain in tension during the epoxy curing. The resin was prepared by mixing the epoxy with hardener at 2:1 $\mathrm{wt} \%$ using a VWR magnetic stirring plate at a $60 \mathrm{rpm}$, at room temperature for $10 \mathrm{~min}$, and was degassed in a vacuum chamber for $5 \mathrm{~min}$ prior to pouring into the mold. SFF test specimens were prepared using the following GF: GF, 0.5S-GF, 1S-GF, 1.5S-GF, 2S-GF, 3S-GF, and 5S-GF. The SFF test dogbone specimens were made according to the test protocol for SFF test [27], having a gauge length of $25 \mathrm{~mm}$ long, $3 \mathrm{~mm}$ wide and a depth of $2 \mathrm{~mm}$, with an overall length and width of 80 and $10 \mathrm{~mm}$, respectively.

GF/epoxy composites were produced with a $30 \mathrm{wt} \%$ GF content. Chopped GF rovings with or without $\mathrm{CNC}$ coatings were added and mixed with the resin using a spatula in a tote and degassed in a vacuum chamber, for $5 \mathrm{~min}$. Then, the mixture was spread in a rectangular mold and cured as described above. Based on the SFF results (see Section 3.2), only 1SGF, 1.5S-GF and 2S-GF were used to make CNCGF/epoxy composites. The test coupons were cut from the plate using a waterjet (MAXIEM 1515).

\subsection{Characterization techniques}

\subsubsection{Single-fiber fragmentation tests (SFF)}

SFF tests, as described by Hunston et al. [27], were used to quantify the effect of $\mathrm{CNC}$ coatings on the IFSS. In brief, tensile tests, with applied load along the fiber axis direction, were carried out at a displacement rate of $1 \mathrm{~mm} / \mathrm{min}$ using an Instron 33R 4466 equipped with a $500 \mathrm{~N}$ load cell. The tests continued until the load passed its peak and dropped at $90-95 \%$ of maximum load to ensure that no further fiber fragmentation could occur. Since the GF were pre-strained, it was expected that when the epoxy reached at its strain to failure, saturation in the GF fragmentation had occurred. It is noted that if the test continued further than this point, the samples would break into two pieces and the fragmentation lengths could not be recorded. The IFSS was determined by Kelly and Tyson model [28] given in Equation (1):

$\tau_{\mathrm{i}}=\frac{d_{\mathrm{f}} \sigma_{\mathrm{f}}\left(l_{\mathrm{c}}\right)}{2 l_{\mathrm{c}}}=\frac{3 d_{\mathrm{f}} \sigma_{\mathrm{f}}\left(l_{\mathrm{c}}\right)}{8 \bar{l}}$

where $\tau_{\mathrm{i}}$ is the IFSS, $d_{\mathrm{f}}$ is the fiber diameter, $l_{\mathrm{c}}$ is the fiber critical fragmentation length, $\bar{l}$ is the average length of fiber fragmentation segments $\left(l_{\mathrm{c}}=4 \bar{l} / 3\right)$ and $\sigma_{\mathrm{f}}$ is the fiber strength at the critical length. The fiber diameter and fiber fragmentation lengths were measured using polarized microscopy. The GF fiber strength was estimated by tensile testing (ASTM D3822), where a single GF fiber was attached to a paper tab and tested at a displacement rate of $1 \mathrm{~mm} / \mathrm{min}$ using the Instron. An average GF strength of $2900 \pm 350 \mathrm{MPa}$ was measured for a gauge length of $25.4 \mathrm{~mm}$ and as expected, the CNC coating process did not affect the single GF ultimate strength. Both the strength value and the IFSS values reported are an average of at least 10 measurements. Weibull distribution was applied for the GF strength data [29] to obtain the Weibull modulus and fiber strength as 4.57 and $2900 \mathrm{MPa}$ respectively. These values were used to extrapolate the GF strength at the critical length required in Equation (1).

\subsubsection{Microscopy}

A Leica DM2500 polarized light optical microscope was used to characterize $\mathrm{CNC}$ coatings on chopped GF rovings, and to measure the fiber fragmentation lengths in SFF tests. A Hitachi SU 8230 field emission scanning electron microscope (FE-SEM) at an acceleration of $5 \mathrm{kV}$ were used to view the $\mathrm{CNC}$ coat- 
ings on individual GF, and the fracture surfaces of the composites. A plasma sputter (Ted Pella Inc.) was used to apply gold coating on the surface of the samples prior to SEM imaging to minimize charging.

\subsubsection{Specific density, thermal stability and CNC content}

Water displacement method was used to measure the specific density of the composites according to ASTM D-792. Thermogravimetry analysis (TGA), using TGA SDT Q600 (TA Instruments), was used to assess the thermal stability of CNC and determine the $\mathrm{CNC}$ content on the GF. The samples were heated from 50 to $500^{\circ} \mathrm{C}$ at $10^{\circ} \mathrm{C} / \mathrm{min}$ in inert atmosphere. Each data point is an average of at least 3 measurements.

\subsubsection{Mechanical and dynamic mechanical testing}

The tensile properties of the composites were determined according to ASTM D638 using an Instron 33R 4466 equipped with $10 \mathrm{kN}$ load cell. An extensometer, Instron 2630-35, with a gauge length of $50.8 \mathrm{~mm}$ was used. The modulus was calculated between the axial strain values of 0.05 and $0.2 \%$. Each tensile data point is an average of at least five samples. The flexural properties were measured using three-point bending tests with an Instron 33R 4466 equipped with $10 \mathrm{kN}$ load cell according to ASTM D790-02 with a support span of $50 \mathrm{~mm}$ and a sample thickness of $5 \mathrm{~mm}$ at a displacement rate of $0.85 \mathrm{~mm} / \mathrm{min}$. Each flexural data point is an average of at least seven tests. Dynamic mechanical thermal analyses (DMA Q800, TA Instruments) in three-point bending mode was used to measure the storage and loss moduli and the glass transition temperature $\left(T_{\mathrm{g}}\right)$ in the $25-160^{\circ} \mathrm{C}$ range at a heating rate of $5^{\circ} \mathrm{C} / \mathrm{min}$ and $1 \mathrm{~Hz}$. A preload of $0.01 \mathrm{~N}$ and a maximum strain of $0.05 \%$ were applied on the specimens. Each data point is an average of at least five tests.

\section{Results and discussion}

In order to test the hypothesis that addition of CNC on the GF/epoxy interphase can improve the mechanical properties of the composites, composites with uncoated and CNC coated GF were compared in terms of mechanical properties. First, it was determined whether or not the CNC alter the GF/epoxy interphase (a region around the GF in which the mechanical properties differ from the bulk mechanical properties of the composite) and the optimum $\mathrm{CNC}$ concentration needed to increase the properties of the composites with no weight penalty.

\subsection{CNC coatings on GF}

GF rovings were coated with $\mathrm{CNC}$ according to the process described in Section 2.2. As shown in Figure $1 \mathrm{a}, 1 \mathrm{~b}$, a thin layer of CNC is deposited on the GF surface as a result of physical absorption (e.g. hydrogen bonding of the accessible-OH side groups on the CNC surface as described in Chen et al. [25]). Of interest is how the CNC coated the chopped GF rovings, as well as individual GF within the rovings. To observe the surface of individual GF, the GF were pulled out from the chopped GF rovings after the coating process. As shown in Figure 1c-e, the uncoated GF has a smooth surface, while the surface of $\mathrm{CNC}$ coated $\mathrm{GF}$ is rougher, indicating that $\mathrm{CNC}$ have been deposited on the GF surface. Additionally, the coated GF surface roughness appears to increase with the $\mathrm{CNC}$ coating deposition concentration, suggesting that more $\mathrm{CNC}$ are deposited on the GF surface. Some of the roughness features in the $\mathrm{CNC}$ coating on individual GF is likely associated with the $\mathrm{CNC}$ coating process using the GF rovings as opposed to individual GF, in which GF-GF meniscus formation within GF rovings during drying would cause deposition variations. In addition, deformation of the CNC coating would occur when separating GF from other GF within the GF roving.

The implications of these observations are that although GF rovings are used in the coating process, the $\mathrm{CNC}$ suspension can penetrate the GF rovings and coat individual GF. The differences in the GF surface roughness of individual GF may subsequently alter the stress transfer efficiency at the GF/epoxy interphase in SFF testing that uses individual GF, as seen in Section 3.2, but it is unclear to what extent, roughness will influence the results of the composites testing where much larger-sized chopped GF rovings are used.

\subsection{Interfacial properties}

Figure 2a shows an optical image of a post-tested SFF 0.5S-GF test coupon with three fracture events along the GF, where the distance between each fracture represents an individual fiber fragment length. The average fiber critical length $(=4 \bar{l} / 3$, where is the average of several individual fiber fragment lengths), and the calculated IFSS, as a function of 


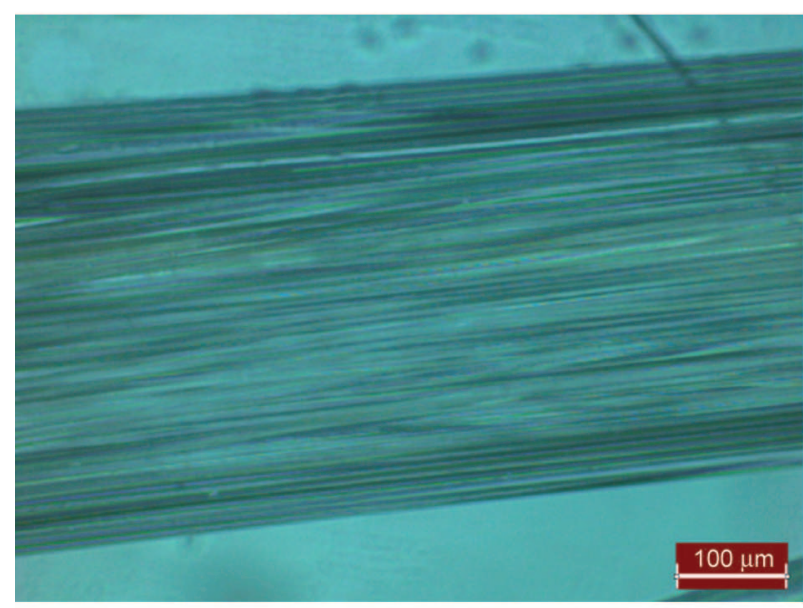

a)

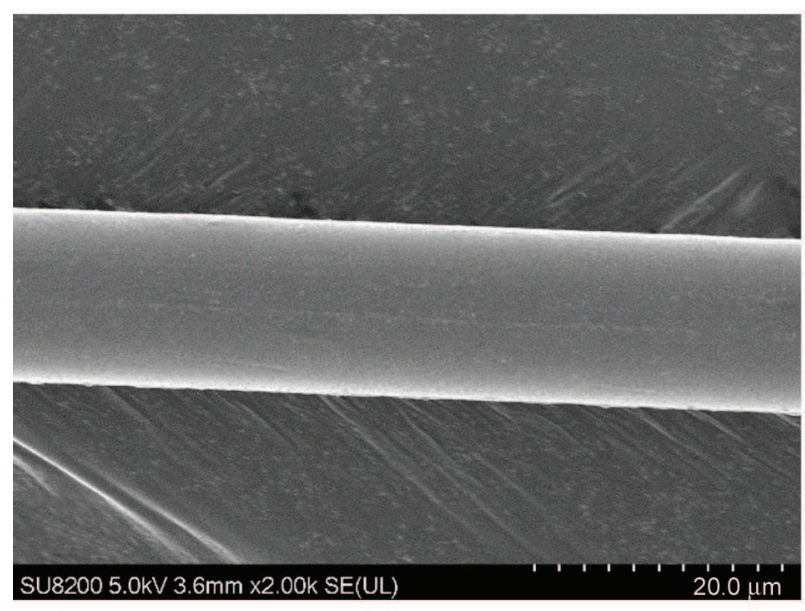

c)

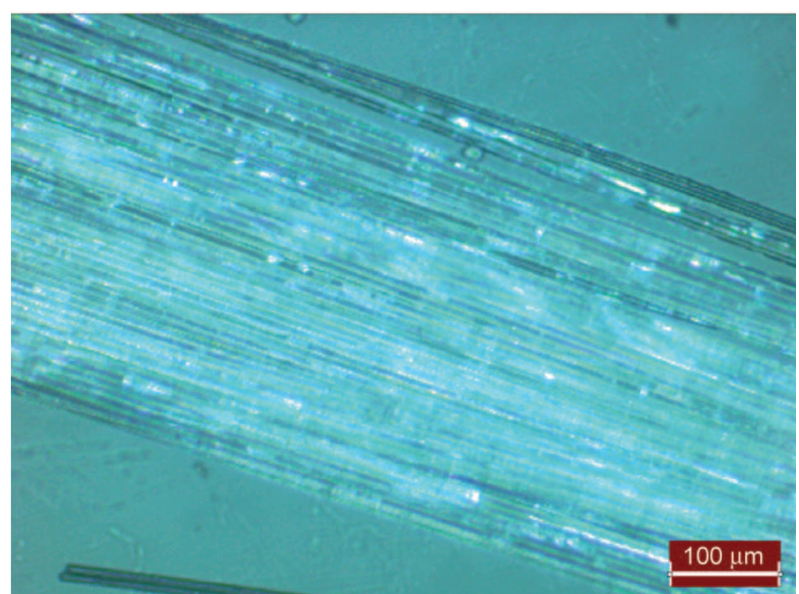

b)

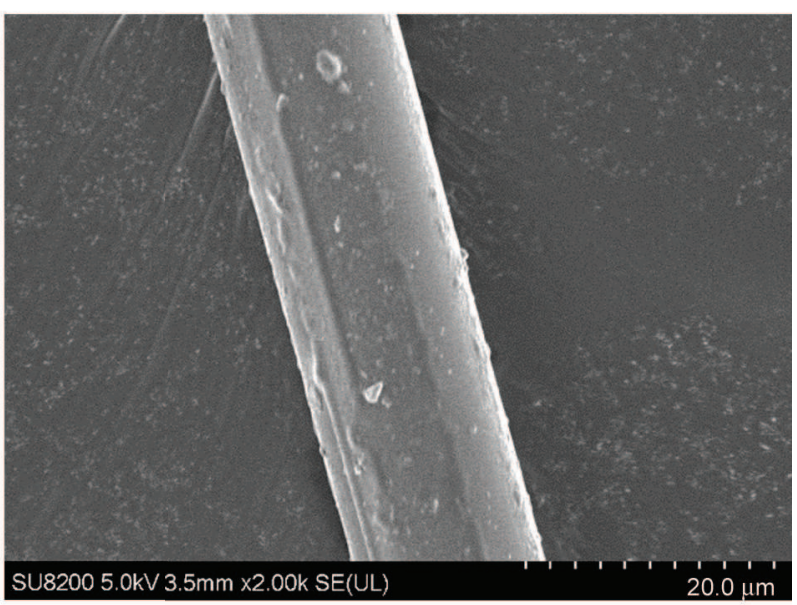

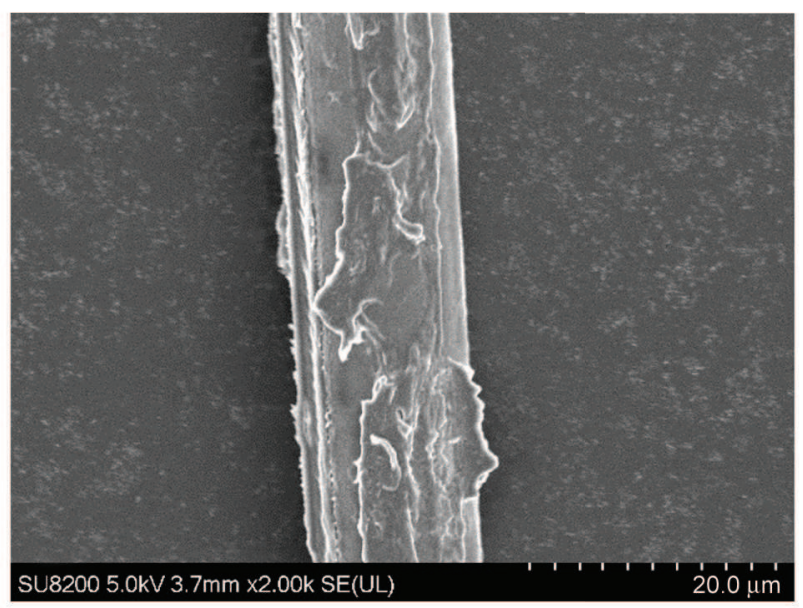

e)

Figure 1. Polarized micrographs (polarized light of $95^{\circ}$ ) of chopped GF rovings, (a) uncoated, and (b) coated 1.5S-GF; SEM images of single GF coated with CNC (c) $0 \mathrm{wt} \%$, (d) $1 \mathrm{wt} \%$ and (e) $5 \mathrm{wt} \%$ suspensions

CNC coating concentration on the GF surface are shown in Figure 2b. Changes in both the IFSS and fiber critical length when the GF are coated indicate that the load transfer across the GF/CNC/epoxy interphase has been modified. Possible mechanism are mechanical interlocking between the GF and epoxy due to the increased GF surface roughness and corresponding increased surface area, as well as differ- ent chemical affinity as a result of the GF having a $\mathrm{CNC}$ coating. There appears to be an optimum condition i.e. $1 \mathrm{~S}-\mathrm{GF}$ for which the IFSS reaches a maximum, that corresponds to $\sim 69 \%$ increase compared to that of the uncoated GF/epoxy specimen. As the concentration of $\mathrm{CNC}$ suspension increases, i.e. for 1.5S-GF, 2S-GF, 3S-GF, and 5S-GF SFF cases, there is a reduction in IFSS. The lower IFSS suggest that 


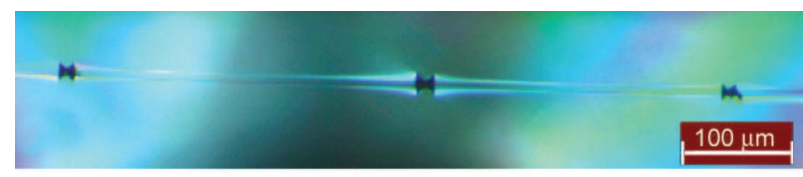

a)

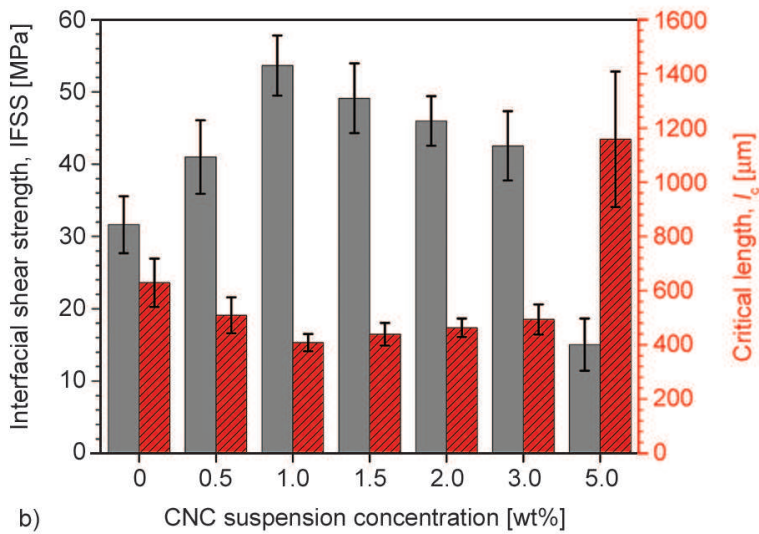

Figure 2. SFF results: (a) Polarized light micrograph of a single GF coated with $0.5 \mathrm{CNC}-\mathrm{GF}$ (polarized light $80^{\circ}$ ) embedded in epoxy showing representative critical fragmentation length, (b) Interfacial shear strength (solid gray bars) and critical fragmentation length (striped red bars) for composites as a function of $\mathrm{CNC}$ suspension concentration. Error bars are 1 standard deviation.

the $\mathrm{CNC}$ coatings have reduced the stress transfer efficiency at the GF/CNC/epoxy interphase. A few mechanisms are plausible, which can be based on the quality of the $\mathrm{CNC}$ coating and associated interfacial defects. As shown in Figure 1e, 5S-GF tend to have rougher surfaces and other defects within the $\mathrm{CNC}$ coating, e.g. formation of $\mathrm{CNC}$ multilayer that can potentially result in slippage of $\mathrm{CNC}$ with respect to each other and reduction of the stress transfer efficiency.

There were various fracture modes observed for the specimens with different $\mathrm{CNC}$ coating contents, suggesting that there is a change in the interfacial properties at the GF-epoxy interface caused by the CNC coatings. According to Mullin and Mazzio [30], fracture modes in single fiber fragmentation tests can be categorized to three modes based on the fiber/matrix level of adhesion; mode $i$ : following the fiber break, a disk shaped matrix crack occurs as a result of normal stresses, shown in Figure 3a, suggesting a strong interface; mode ii: following the fiber break, a double cone-shaped matrix crack with $45^{\circ}$ angle occurs as a result of shear stresses, shown in Figure 3b, referring to a type of interface in which the matrix shear strength is lower than its tensile strength; and mode iii: fiber break is instantly followed by a lim-

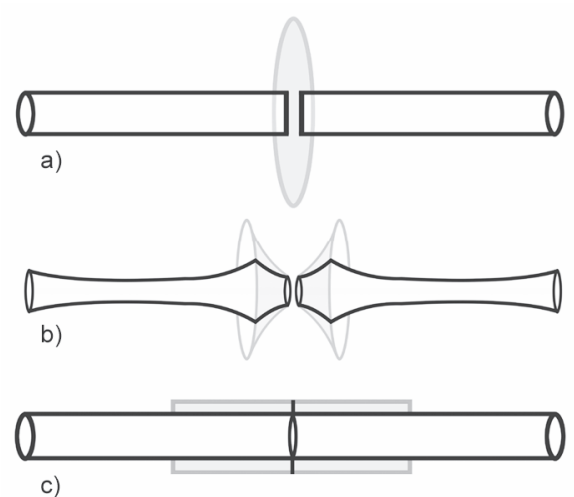

Figure 3. Three modes of fracture in matrix in single fiber fragmentation test; (a) mode $i$ : disk-shaped fracture of matrix referring to strong interface, (b) mode ii: double-cone matrix fracture suggesting a matrix with a low shear strength, and (c) mode iii: debonding of fiber and matrix inferring a weak interface

ited interfacial debonding due to shear stress, shown in Figure 3c, implying a weak interface type. The debonded interface cannot transfer any load from matrix to the fiber and the length of debonding can be used as an indicator of fiber stress and interfacial energy [31]. For epoxies, concurrent disk-shaped and cone-shaped matrix cracks formed at the fiber ends are commonly seen. In the current study, combined fracture modes $i$ and $i i$ along with few cracks of mode iii were observed for the GF and 0.5S-GF samples, as shown in Figure $4 \mathrm{a}-\mathrm{c}$. The fracture mode for 1S-GF, 1.5S-GF, 2-S-GF, and 3S-GF SFF samples were combined modes $i$ and ii, shown in Figure 4d, $4 \mathrm{e}$, suggesting a stronger interfacial bonding compared to uncoated-GF/epoxy samples. The fracture modes for 5S-GF samples were mode ii and mode iii; however, it was observed that the debonded areas increased compared to that of uncoated GF/epoxy samples implying a weaker interface and a lower IFSS value, as seen in Figure 2.

\subsection{Specific density, CNC content and thermal stability}

GF/epoxy composites were made using the following chopped GF rovings: GF, 0.5S-GF, 1S-GF, 1.5SGF and 2S-GF. The density for all these composites was found to be $1.3 \pm 0.03 \mathrm{~g} / \mathrm{cm}^{3}$, delineating that the $\mathrm{CNC}$ coatings did not significantly increase the composite weight and is consistent with the small CNC wt $\%$ deposited on the GF.

The CNC wt $\%$ within chopped GF rovings as well as within the composites was correlated with the $\mathrm{CNC}$ suspension concentration used in the coating 


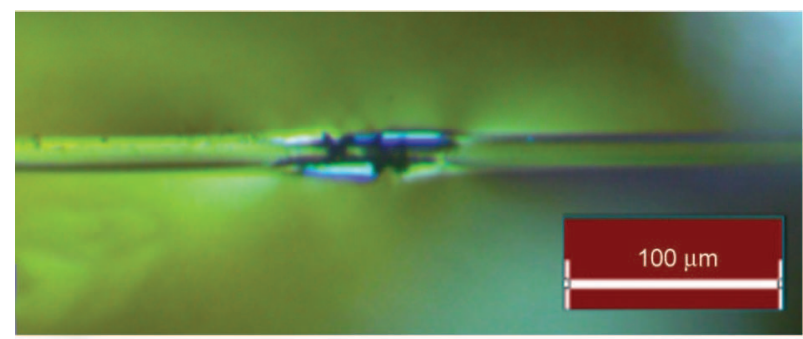

a)

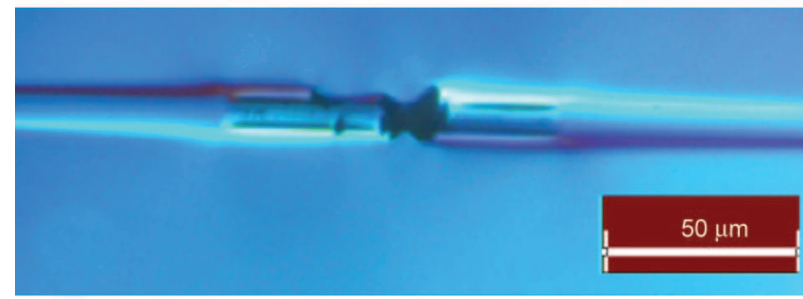

b)

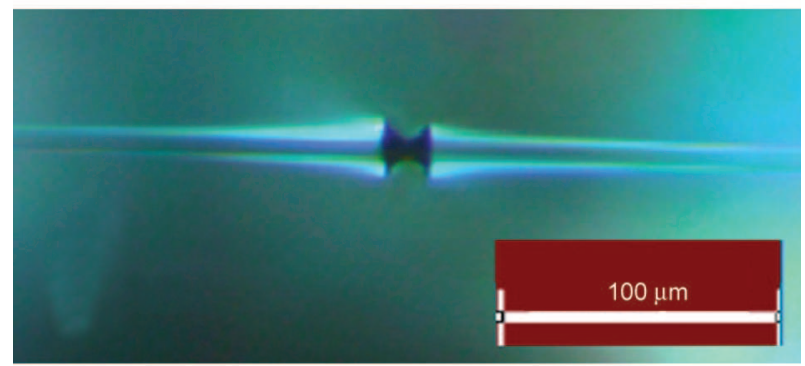

c)

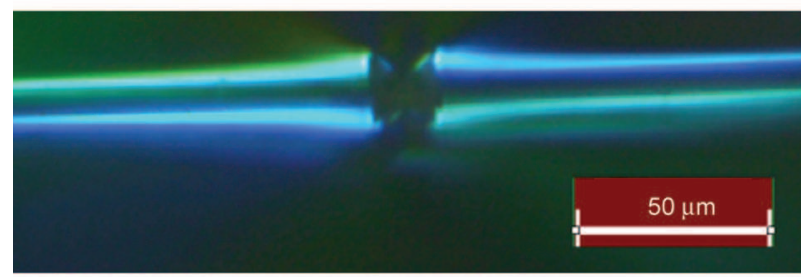

d)

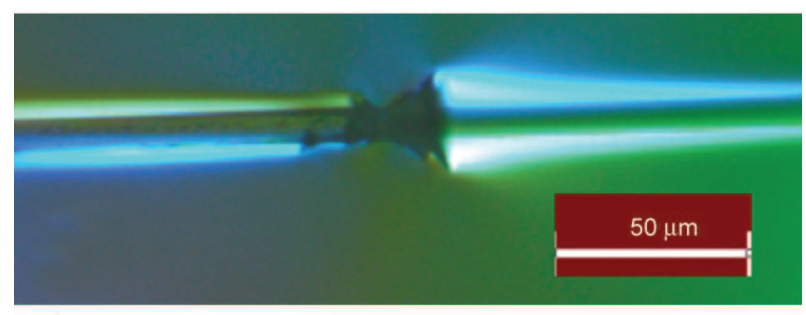

e)

Figure 4. Optical polarized light micrographs of SFF specimens after tensile test showing fracture events at the GF: (a) GF/epoxy (polarized light of $75^{\circ}$ ), (b) $0.5 \mathrm{~S}-\mathrm{GF}$ (polarized light $120^{\circ}$ ), (c) $0.5 \mathrm{~S}-\mathrm{GF}$ (polarized light $80^{\circ}$ ), (d) $1 \mathrm{~S}-\mathrm{GF}$ (polarized light 90) and (e) $2 \mathrm{~S}-\mathrm{GF}$ (polarized light $75^{\circ}$ )

process as shown in Figure 5. The uncoated GF used as the baseline for determining the $\mathrm{CNC} w \mathrm{t} \%$ on the coated GF. The CNC content on the GF surface increased from $0.44 \pm 0.07$ to $3.58 \pm 0.02 \mathrm{wt} \%$ for 0.5 and $5 \mathrm{CNC}$ wt $\%$ suspensions, respectively. It is noted that the $\mathrm{CNC}$ wt $\%$ on the GF surface is not increasing linearly with the $\mathrm{CNC}$ suspension concentration

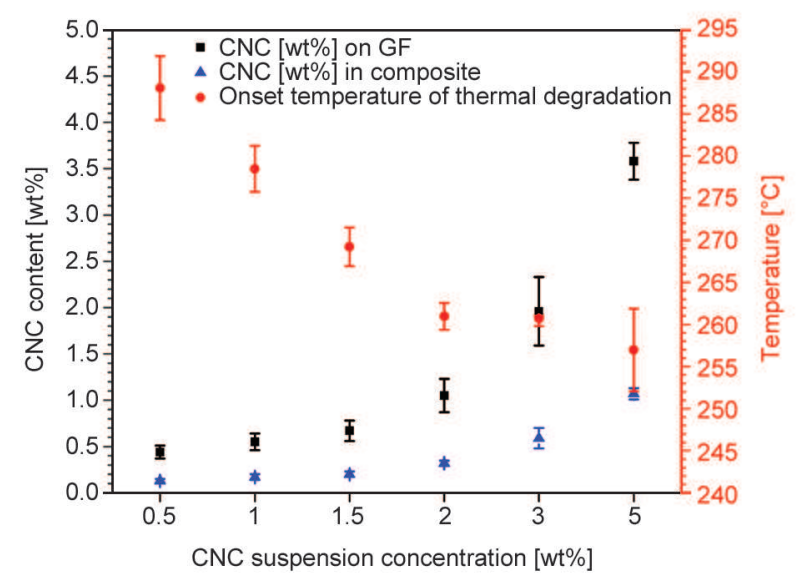

Figure 5. CNC suspension concentration on the GF and composites and onset temperature of thermal degradation for CNC-coated GF as a function of CNC concentration in the aqueous solution. Error bars are 1 standard deviation

used in coating process, e.g. the $\mathrm{CNC}$ content on the GF coated with $1 \mathrm{CNC}$ wt $\%$ solution is not twice of that of the GF coated with $0.5 \mathrm{CNC} w \mathrm{wt} \%$.

The thermal stability of the CNC-coated GF is also plotted in Figure 5. The onset temperature of thermal degradation of the neat $\mathrm{CNC}$ was $234.23 \pm 0.67^{\circ} \mathrm{C}$. All the coated-GF degraded above this temperature (lower bound). The onset temperature of thermal degradation decreased with the increase in the $\mathrm{CNC}$ content on the GF which was expected as it should reach the lower bound with the increase in the $\mathrm{CNC}$ content.

\subsection{Fracture surface morphology}

The fracture surface of the composites failed in the tensile testing was studied using a FE-SEM. As shown in Figure 6a, 6b, the main failure mechanism for uncoated GF epoxy composites was interfacial debonding as indicated by the clean pulled-out fibers devoid of the matrix, suggesting weak fiber-matrix adhesion. In contrast, the failure mechanisms for $\mathrm{CNC}$ coated GF epoxy composites were concurrent matrix cracking, fiber breakage and interfacial debonding, shown in Figure 6c, 6d, implying an improvement in the interfacial bonding as a result of $\mathrm{CNC}$ coating. Also, matrix residues on the pulled-out fibers (Figure $6 \mathrm{~d}$ ) and a rough fracture surface for both 1S30GF/epoxy and 2S-30GF/epoxy composites compared to the smooth fracture surface for the uncoated GF/epoxy composites suggest a better adhesion between fiber and matrix. 


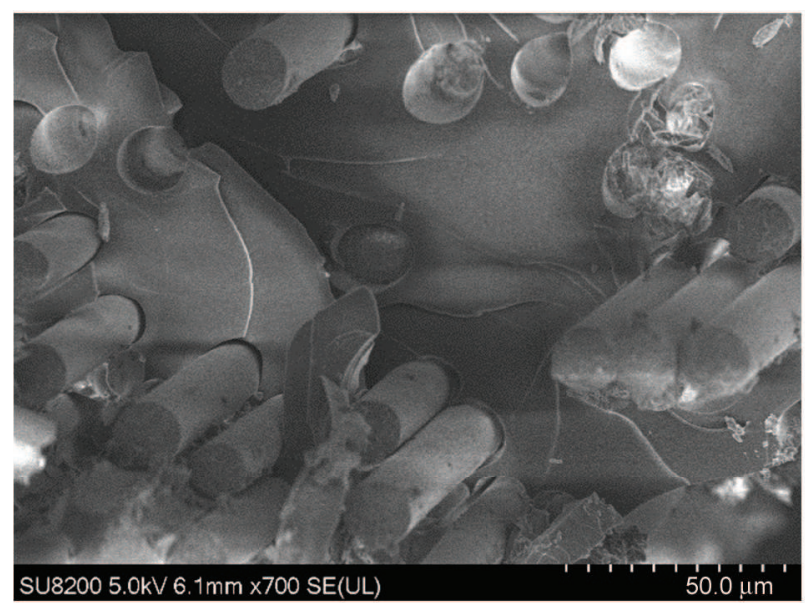

a)

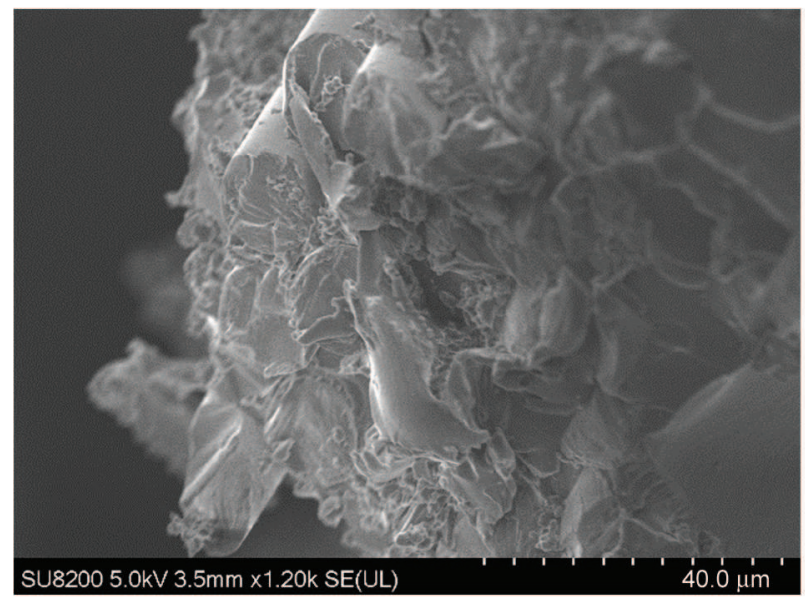

c)

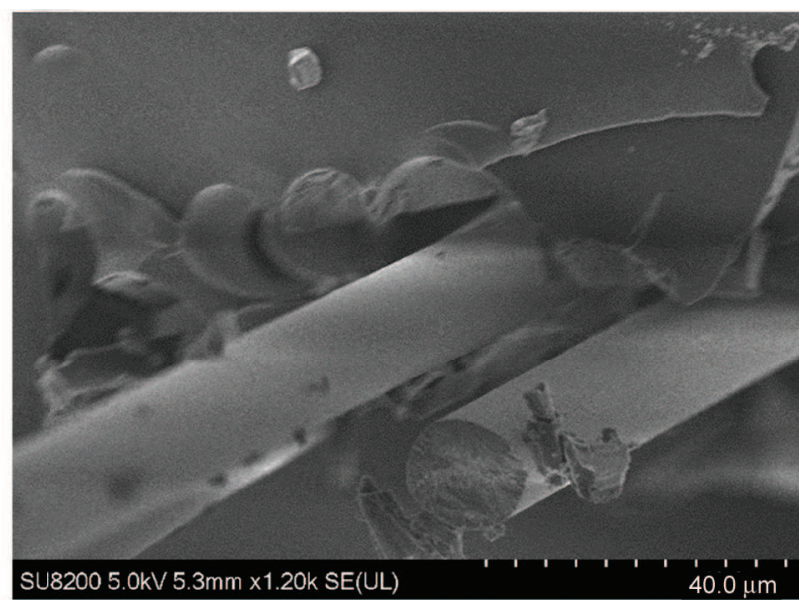

b)

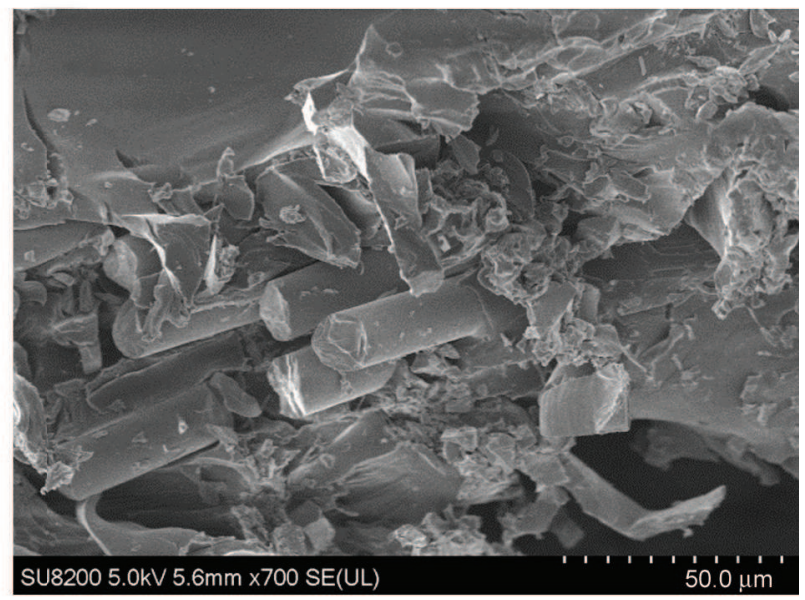

d)

Figure 6. SEM images for fracture surface of different epoxy composites; (a) and (b) uncoated 30GF/epoxy, (c) 1S-30GF/ epoxy, (d) 2S-30GF/epoxy

\subsection{Tensile and flexural properties}

The effect of the CNC content on the tensile and flexural properties of $\mathrm{CNC}$ coated GF/epoxy composites are plotted in Figure 7. The incorporation of $\mathrm{CNC}$ as a coating to $\mathrm{GF}$ enhances the elastic modulus by $\sim 10 \%$ for $1 \mathrm{~S}-30 \mathrm{GF} /$ epoxy and $1.5 \mathrm{~S}-30 \mathrm{GF} /$ epoxy composites with respect to that of uncoated GF/epoxy. This may be a result of the increase in the stiffness of the GF/epoxy interphase due to presence of $\mathrm{CNC}$ as according to Hashin [32], for an imperfect interface (i.e. displacement discontinuity across the interface) an interfacial stiffness parameter can be defined where a higher value of this parameter suggests a faster rate of stress transfer across the fiber/matrix interface and thus a higher modulus for the composite [33]. Although this hypothesis could not be validated in this study, Gao and Mäder [34] showed how increases in the apparent modulus at the GF/epoxy interphase resulted in increase in the composite macroscopic modulus, which can be qualita- tively linked to the current study where enhancement in the apparent modulus of the GF/epoxy interphase resulted in higher macroscopic modulus of the composites. In addition, the tensile strength increased for $1 \mathrm{~S}-30 \mathrm{GF} /$ epoxy $(\sim 10 \%)$ and $1.5 \mathrm{~S}-30 \mathrm{GF} /$ epoxy composites with respect to that of $30 \mathrm{GF} /$ epoxy composites. This increase reflects the higher IFSS (see Figure 2) inferring stronger interfacial interactions and better stress transfer across the fiber/CNC/epoxy interphase as also reported elsewhere [35]. The tensile strength of the $2 \mathrm{~S}-30 \mathrm{GF} /$ epoxy composite was $\sim 12 \%$ lower despite having higher IFSS compared to that of $30 \mathrm{GF} /$ epoxy. This may be due to various mechanisms including void formation within and around the GF rovings as a result of incomplete infiltration of the epoxy within the coated GF rovings and breaking of the $\mathrm{CNC}$ coating as it becomes more brittle with increase of its thickness. The strain at break had a trend similar to that of the strength, where the strain at break in $1 \mathrm{~S}-30 \mathrm{GF} /$ epoxy and 


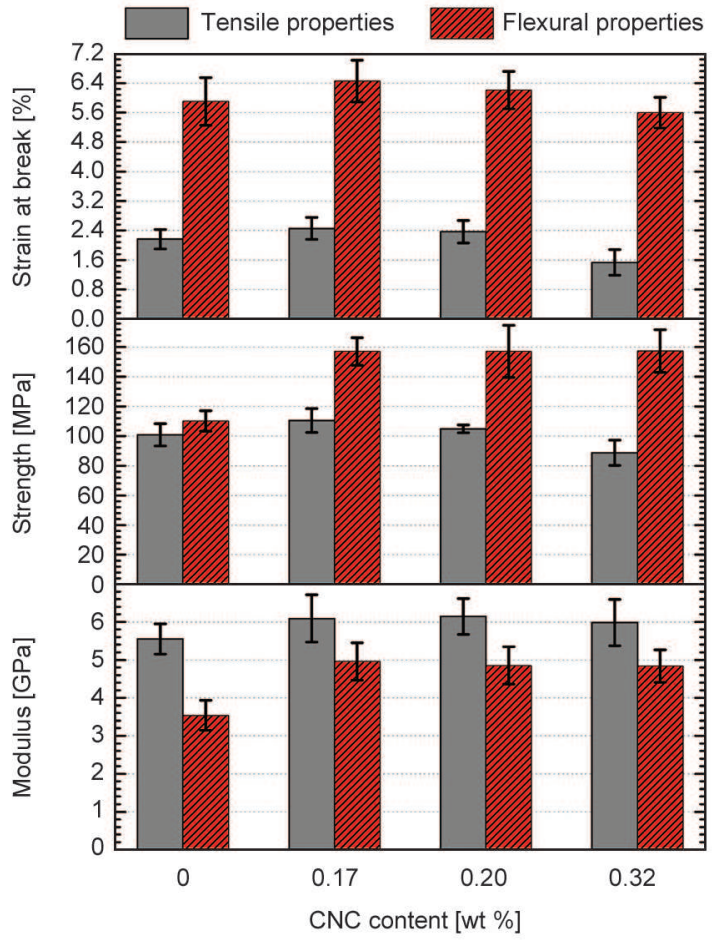

Figure 7. Effect of the $\mathrm{CNC}$ content (wt $\%$ in composite) in CNC-coated 30GF/epoxy composites on tensile and flexural properties. Error bars are 1 standard deviation

1.5S-30GF/epoxy composites increased by $\sim 14$ and $\sim 10 \%$ while that of $2 \mathrm{~S}-30 \mathrm{GF} / \mathrm{epoxy}$ decreased compared to uncoated $30 \mathrm{GF} /$ epoxy composites.

For composites made with $1 \mathrm{~S}-\mathrm{GF}$ and $1.5 \mathrm{~S}-\mathrm{GF}$, the flexural modulus and strength increased by $\sim 40$ and $\sim 42 \%$, respectively, with respect to those of uncoated 30GF/epoxy composites indicating better adhesion between the glass fiber and epoxy due to higher IFSS, and stress transfer at a faster rate as discussed above. The strain at break follows similar trend to that of axial strain, where it increased by $\sim 10 \%$ for 1S-30GF/epoxy.

It is noted that the enhancement in flexural properties was larger than the enhancement in tensile properties at the same $\mathrm{CNC}$ content. The differences in elastic moduli and strengths may result from the difference in tensile and flexural moduli of the epoxy resin. In most epoxy systems, the tensile modulus is higher than the flexural modulus while the tensile strength is lower than the flexural strength (e.g. report by Kinsella et al. [36]). In addition, for the strength and the strain at break, a different mechanism may be at play since these properties are typically dominated by defects within the composite. For materials with defect mediated failure, strength and strain at break properties will be dependent on the number of defects, their size, where they are located with respect to the high stressed portions of the sample and volume subjected to the highest tensile stress. For the samples used in tensile and flexural testing, it is likely that the defect numbers and size distributions are similar in all samples tested; however, in the tensile coupons, all the material in the gauge portion experiences the maximum stress as compared to the to the flexural sample configuration in which only the outer surfaces of specimen are subjected to the maximum stress. With this in mind, for the tensile testing, there is higher probability that a larger number of defects is located in the high tensile stressed portions of the sample and because of this, a lower applied load would be needed to induce fracture. Moreover, the larger enhancement of the flexural properties compared to the enhancement of the tensile properties can be due to the fact that the glass fibers are randomly oriented in plane so that in tensile loading only a portion of their length along the direction of the applied load will bear loading. In case of the threepoint bending, the load direction is out of plane and all the fibers (across the whole length) are available to take up load and therefore enhancement in the flexural properties would be higher.

\subsection{Dynamic thermo-mechanical properties}

The dynamic thermo-mechanical properties of the composites below and above $T_{\mathrm{g}}$ are presented in Table 1 . At $25^{\circ} \mathrm{C}$, the incorporation of $\mathrm{CNC}$ as a coating to GF rovings was shown to enhance the storage modulus $\left(E^{\prime}\right)$ for the $1 \mathrm{~S}-30 \mathrm{GF} /$ epoxy and $1.5 \mathrm{~S}-30 \mathrm{GF} /$ epoxy composites, but lower the storage modulus for 2S-30GF/epoxy composites, as compared to that of $30 \mathrm{GF} /$ epoxy composites. The increase in the storage modulus at $25^{\circ} \mathrm{C}$ can be attributed to the stiffening of the $\mathrm{GF} / \mathrm{CNC} /$ matrix interphase due to presence of $\mathrm{CNC}$ particles, as discussed in Section 3.5. Although the average value of the rubbery moduli $\left(E_{\mathrm{r}}\right.$ : the storage modulus above $T_{\mathrm{g}}$ ) measured at $90^{\circ} \mathrm{C}$ for the composites containing $\mathrm{CNC}$-coated $\mathrm{GF}$ were lower than that of the composite incorporating uncoated GF, due to the large standard deviation in measured properties, it was concluded that coating of the GF with CNC did not impact the rubbery modulus. Studies have shown that addition of $\mathrm{CNC}$ in the epoxy increased the rubbery modulus due to the formation of a network of mechanically percolated CNC [16, $18,21]$. However, it is expected that CNC on the surface of the GF do not form a percolated network 
Table 1. Viscoelastic properties of CNC-GF/epoxy composites in three-point bending mode

\begin{tabular}{|l|c|c|c|c|}
\hline \multicolumn{1}{|c|}{ Composite } & $\begin{array}{c}\boldsymbol{E}^{\prime} \text { at } \mathbf{2 5}^{\circ} \mathbf{C} \\
{[\mathbf{M P a}]}\end{array}$ & $\begin{array}{c}\boldsymbol{E}_{\mathbf{r}} \text { at } \mathbf{9 0}^{\circ} \mathbf{C} \\
{[\mathbf{M P a}]}\end{array}$ & $\begin{array}{c}\boldsymbol{T}_{\mathbf{g}} \\
{\left[{ }^{\circ} \mathbf{C}\right]}\end{array}$ & $\tan \boldsymbol{\delta}$ at $\boldsymbol{T}_{\mathrm{g}}$ \\
\hline 30GF/epoxy & $4932 \pm 586$ & $250 \pm 21$ & $50.3 \pm 0.7$ & $0.61 \pm 0.06$ \\
\hline 1S-30GF/epoxy & $5213 \pm 543$ & $224 \pm 31$ & $49.4 \pm 0.5$ & $0.61 \pm 0.02$ \\
\hline 1.5S-30GF/epoxy & $5614 \pm 695$ & $228 \pm 22$ & $50.2 \pm 0.8$ & $0.65 \pm 0.07$ \\
\hline 2S-30GF/epoxy & $4634 \pm 257$ & $243 \pm 38$ & $49.5 \pm 1.1$ & $0.59 \pm 0.02$ \\
\hline
\end{tabular}

$E^{\prime}$ : storage modulus

$E_{\mathrm{r}}$ : rubbery modulus

$T_{\mathrm{g}}$ : glass transition temperature measured in $\tan \delta$ peak

$\tan \delta$ : value of $\tan \delta$ peak

Note: Error bars are 1 standard deviation.

within the polymer matrix. Hence, CNC cannot strongly impact the polymer chain segmental motion and consequently, the rubbery modulus. Presence of $\mathrm{CNC}$ has no effect on the $\tan \delta$ and the glass transition temperature $\left(T_{\mathrm{g}}\right)$.

\section{Conclusions}

This study demonstrated that introducing a small amount of $\mathrm{CNC}$ in the form of a coating on GF can enhance the IFSS and mechanical properties of short GF/epoxy composites without increasing the weight. The proposed mechanism for altering the composite properties is the improvement of the interfacial adhesion and stress transfer ability and rate across the GF/epoxy interphase due to the CNC coating. Single fiber fragmentation tests showed that coating of GF up to $1.96 \mathrm{wt} \%$ (coated in $3 \mathrm{wt} \%$ aqueous CNC suspension) was able to increase IFSS; however, the highest increase in IFSS (by 69\%) was achieved for CNC coating of $0.55 \mathrm{wt} \%$ (coated in $\mathrm{CNC} 1 \mathrm{wt} \%$ aqueous $\mathrm{CNC}$ suspension). The CNC-GF/epoxy composites produced using $\mathrm{CNC}$ coated chopped GF roving showed increases in tensile and flexural properties, which were attributed to the increase in IFSS associated with the application of the GF coatings. The greatest improvement in properties occurred when $\mathrm{CNC}$ coating on GF rovings equal to $0.17 \mathrm{wt} \%$ of composite was used. Specifically, the tensile elastic modulus and strength by $\sim 10 \%$, tensile strain at break by $\sim 14 \%$, the flexural modulus and strength by $\sim 40 \%$ and flexural strain at break by $\sim 10 \%$. It is noted that the $\mathrm{CNC}$ coating did not significantly alter the rubbery modulus, $T_{\mathrm{g}}$ and $\tan \delta$. The results highlight that the use of CNC coatings on GF, is a possible approach for enhancing the mechanical properties of GF/epoxy composites with no weight penalty.

\section{Acknowledgements}

This work was supported by funding from $\mathrm{P}^{3}$ Nano and the U.S. Endowment for Forestry and Communities. The authors would like to thank Prof. Jon Colton for providing mechanical testing equipment.

\section{References}

[1] U. S. Department of Energy: The quadrennial technology review. p.39 (2011).

[2] Dorigato A., Morandi S., Pegoretti A.: Effect of nanoclay addition on the fiber/matrix adhesion in epoxy/ glass composites. Journal of Composite Materials, 46, 1439-1451 (2012). DOI: $10.1177 / 0021998311420311$

[3] Pedrazzoli D., Pegoretti A., Kalaitzidou K.: Synergistic effect of exfoliated graphite nanoplatelets and short glass fiber on the mechanical and interfacial properties of epoxy composites. Composites Science and Technology, 98, 15-21 (2014).

DOI: $10.1016 /$ j.compscitech.2014.04.019

[4] Pedrazzoli D., Pegoretti A.: Silica nanoparticles as coupling agents for polypropylene/glass composites. Composites Science and Technology, 76, 77-83 (2013). DOI: 10.1016/j.compscitech.2012.12.016

[5] Gao S-L., Mäder E., Plonka R.: Nanocomposite coatings for healing surface defects of glass fibers and improving interfacial adhesion. Composites Science and Technology, 68, 2892-2901 (2008).

DOI: 10.1016/j.compscitech.2007.10.009

[6] Luo J-J., Daniel I. M.: Characterization and modeling of mechanical behavior of polymer/clay nanocomposites. Composites Science and Technology, 63, 16071616 (2003). DOI: $10.1016 / \mathrm{S} 0266-3538(03) 00060-5$

[7] Hubbe M. A., Rojas O. J., Lucia L. A., Sain M.: Cellulosic nanocomposites: A review. BioResources, 3, 929980 (2008).

[8] Habibi Y., Lucia L. A., Rojas O. J.: Cellulose nanocrystals: Chemistry, self-assembly, and applications. Chemical Reviews, 110, 3479-3500 (2010). DOI: $10.1021 / \mathrm{cr} 900339 \mathrm{w}$

[9] Moon R. J., Martini A., Nairn J., Simonsen J., Youngblood J.: Cellulose nanomaterials review: Structure, properties and nanocomposites. Chemical Society Reviews, 40, 3941-3994 (2011). DOI: $10.1039 / \mathrm{COCS} 00108 \mathrm{~B}$

[10] Roman M.: Toxicity of cellulose nanocrystals: A review. Industrial Biotechnology, 11, 25-33 (2015). DOI: 10.1089/ind.2014.0024

[11] Hansen, F., Brun, V., Keller, E., Wegner, T., Meador, M., Friedersdorf, L.: Cellulose nanomaterials-A Path towards commercialization. USDA Forest Service Workshop report, Washington (2014).

[12] Beck-Candanedo S., Roman M., Gray D. G.: Effect of reaction conditions on the properties and behavior of wood cellulose nanocrystal suspensions. Biomacromolecules, 6, 1048-1054 (2005).

DOI: $10.1021 / \mathrm{bm} 049300 \mathrm{p}$ 
[13] Lee K-Y., Aitomäki Y., Berglund L. A., Oksman K., Bismarck A.: On the use of nanocellulose as reinforcement in polymer matrix composites. Composites Science and Technology, 105, 15-27 (2014). DOI: 10.1016/j.compscitech.2014.08.032

[14] Xu S., Girouard N., Schueneman G., Shofner M. L., Meredith J. C.: Mechanical and thermal properties of waterborne epoxy composites containing cellulose nanocrystals. Polymer, 54, 6589-6598 (2013).

DOI: $10.1016 /$ j.polymer.2013.10.011

[15] Ruiz M. M., Cavaillé J. Y., Dufresne A., Graillat C., Gérard J-F.: New waterborne epoxy coatings based on cellulose nanofillers. Macromolecular Symposia, 169, 211-222 (2001).

DOI: $10.1002 / 1521-3900(200105) 169: 1<211:: A I D-$ MASY211>3.0.CO;2-H

[16] Tang L., Weder C.: Cellulose whisker/epoxy resin nanocomposites. ACS Applied Materials and Interfaces, 2, 1073-1080 (2010). DOI: $10.1021 / \mathrm{am} 900830 \mathrm{~h}$

[17] Lu J., Askeland P., Drzal L. T.: Surface modification of microfibrillated cellulose for epoxy composite applications. Polymer, 49, 1285-1296 (2008).

DOI: $10.1016 /$ j.polymer.2008.01.028

[18] Girouard N., Schueneman G. T., Shofner M. L., Meredith J. C.: Exploiting colloidal interfaces to increase dispersion, performance, and pot-life in cellulose nanocrystal/waterborne epoxy composites. Polymer, 68, 111-121 (2015).

DOI: 10.1016/j.polymer.2015.05.009

[19] Gabr M. H., Elrahman M. A., Okubo K., Fujii T.: A study on mechanical properties of bacterial cellulose/ epoxy reinforced by plain woven carbon fiber modified with liquid rubber. Composites Part A: Applied Science and Manufacturing, 41, 1263-1271 (2010).

DOI: $10.1016 /$ j.compositesa.2010.05.010

[20] Peng S. X., Moon R. J., Youngblood J. P.: Design and characterization of cellulose nanocrystal-enhanced epoxy hardeners. Green Materials, 2, 193-205 (2014). DOI: $10.1680 /$ gmat.14.00015

[21] Ansari F., Galland S., Johansson M., Plummer C. J. G., Berglund L. A.: Cellulose nanofiber network for moisture stable, strong and ductile biocomposites and increased epoxy curing rate. Composites Part A: Applied Science and Manufacturing, 63, 35-44 (2014). DOI: $10.1016 /$ j.compositesa.2014.03.017

[22] Barari B., Ellingham T. K., Ghamhia I. I., Pillai K. M., El-Hajjar R., Turng L-S., Sabo R.: Mechanical characterization of scalable cellulose nano-fiber based composites made using liquid composite molding process. Composites Part B: Engineering, 84, 277-284 (2016). DOI: 10.1016/j.compositesb.2015.08.040

[23] Miao C., Hamad W. Y.: Cellulose reinforced polymer composites and nanocomposites: A critical review. Cellulose, 20, 2221-2262 (2013). DOI: $10.1007 / \mathrm{s} 10570-013-0007-3$

[24] Karger-Kocsis J., Mahmood H., Pegoretti A.: Recent advances in fiber/matrix interphase engineering for polymer composites. Progress in Materials Science, 73, 1-43 (2015).

DOI: $10.1016 /$ j.pmatsci.2015.02.003
[25] Chen Y., Zhou X., Yin X., Lin Q., Zhu M.: A novel route to modify the interface of glass fiber-reinforced epoxy resin composite via bacterial cellulose. International Journal of Polymeric Materials and Polymeric Biomaterials, 63, 221-227 (2013).

DOI: $10.1080 / 00914037.2013 .830250$

[26] Postek M. T., Moon R. J., Rudie A. W., Bilodeau M. A.: Production and applications of cellulose. Tappi Press. Peachtree Corners (2013).

[27] Rich M. J., Drzal L. T., Hunston D., Holmes G., McDonough W.: Round robin assessment of the single fiber fragmentation test. in 'Procedings of the American Society for Composites $17^{\text {th }}$ Technical Conference, West Lafayette, USA' p.10 (2002).

[28] Kelly A., Tyson W.: Tensile properties of fibre-reinforced metals: Copper/tungsten and copper/molybdenum. Journal of the Mechanics and Physics of Solids, 13, 329-350 (1965). DOI: $10.1016 / 0022-5096(65) 90035-9$

[29] Klein C. A.: Characteristic strength, Weibull modulus, and failure probability of fused silica glass. Optical Engineering, 48, 113401/1-113401/11 (2009). DOI: $10.1117 / 1.3265716$

[30] Mullin J. V., Mazzio V. F.: The effects of matrix and interface modification on local fractures of carbon fibers in epoxy. Journal of the Mechanics and Physics of Solids, 20, 391-394 (1972).

DOI: $10.1016 / 0022-5096(72) 90016-6$

[31] Zhou X-F., Nairn J. A., Wagner H. D.: Fiber-matrix adhesion from the single-fiber composite test: Nucleation of interfacial debonding. Composites Part A: Applied Science and Manufacturing, 30, 1387-1400 (1999). DOI: $10.1016 /$ S1359-835X(99)00043-3

[32] Hashin Z.: Thermoelastic properties of fiber composites with imperfect interface. Mechanics of Materials, 8 , 333-348 (1990).

DOI: $10.1016 / 0167-6636(90) 90051-G$

[33] Nairn J. A.: Generalized shear-lag analysis including imperfect interfaces. Advanced Composites Letters, 13, 263-274 (2004).

[34] Gao S-L., Mäder E.: Characterisation of interphase nanoscale property variations in glass fibre reinforced polypropylene and epoxy resin composites. Composites Part A: Applied Science and Manufacturing, 33, 559576 (2002). DOI: $10.1016 / \mathrm{S} 1359-835 \mathrm{X}(01) 00134-8$

[35] Madhukar M. S., Drzal L. T.: Fiber-matrix adhesion and its effect on composite mechanical properties: II. Longitudinal $\left(0^{\circ}\right)$ and transverse $\left(90^{\circ}\right)$ tensile and flexure behavior of graphite/epoxy composites. Journal of Composite Materials, 25, 958-991 (1991).

DOI: $10.1177 / 002199839102500802$

[36] Kinsella M., Murray D., Crane D., Mancinelli J., Kranjc M.: Mechanical properties of polymeric composites reinforced with high strength glass fibers. in ' $33^{\text {rd }}$ International SAMPE Technical Conference, Seatle, USA' Vol. 33, 1644-1657 (2001). 